\title{
Editorial
}

\section{Bodas de Papel On-line: Novo Número para Celebrar o Primeiro Aniversário de Grad+}

\author{
Prof. Thiago Mio Salla e Prof. Eder Cassola Molina
}

$\mathrm{O}$ anúncio feito em março, no terceiro número deste periódico, agora se confirma: a Revista de Graduação USP (ou tão somente Grad+) chega a seu primeiro ano de vida, dando mais um passo resoluto no sentido de consolidar-se como fórum aberto à reflexão, ao debate e ao compartilhamento de pesquisas teóricas e empíricas, experiências pedagógicas e práticas de ensino no âmbito da graduação. Ao longo dessa trajetória curta, mas já frutífera, alcançamos a marca de trinta artigos e cinquenta relatos publicados. Tal material diversificado, quer em nosso site, quer em nossa página no Portal de Revistas da USP, totaliza mais de 5 mil downloads e uma infinidade de page views.

Para além dos números, Grad+ destaca-se pelo compromisso de recolher em suas páginas trabalhos não só relevantes ao ensino-aprendizagem em áreas específicas, mas também capazes de serem replicados em diferentes contextos. Supõe-se que essa busca permanente por apresentar resultados (consolidados ou parciais) de boas práticas pedagógicas passíveis de aplicação em cenários diversos fez com que a revista, embora neófita, já seja classificada como B2 na área "Ensino", em avaliação recente promovida pelo sistema Qualis Periódicos. Se o fato de ter alcançado tal posição em curto espaço de tempo serve de estímulo para prosseguirmos nossa jornada, o que ainda mais nos motiva é a acolhida da publicação entre a comunidade acadêmica e a possibilidade de ela continuar a ressoar, enquanto locus editorial capaz de conferir unidade ao disperso, nas investigações e experiências docentes realizadas em Instituições de Ensino Superior (IES) do país.

Não por acaso, esta edição de Grad+ ratifica, em termos qualitativos e quantitativos, essa recente tradição instaurada pelo periódico: são oito artigos e dezessete relatos, que abarcam as mais variadas áreas do conhecimento, tratam das múltiplas facetas do ensino em nível superior e demonstram potencial para corroborar estudos e experiências em diferentes cursos de graduação.

Na seção de artigos, logo de saída, destaca-se o texto "Desafios na Formação de Professores de História", de Antonia Terra de Calazans Fernandes, que assinala a importância da integração entre fundamentos teóricos e práticas educativas no âmbito da licenciatura, de modo a fomentar, em sala de aula, posturas docentes ativas e reflexivas. Em seguida, Cristiane Aun Bertoldi e Denise Dantas discorrem de modo detalhado sobre o processo de implantação e manutenção de um acervo físico e digital de materiais que serve de suporte para os cursos de Design e Arquitetura da FAU-USP. Trata-se do projeto Materialize, plataforma aberta, com acesso irrestrito, que resulta da parceria entre a referida faculdade e o Istituto Politecnico di Milano.

Ainda quanto ao emprego de ferramentas de ensino-aprendizagem, Brasilina Passarelli e Fabiana Grieco discutem os desdobramentos da pioneira utilização de um misto de Ambiente Virtual de Aprendizagem (AVA) e repositório de objetos de aprendizagem (LOR) em disciplinas do curso de Biblioteconomia da ECA-USP. Mediante tal iniciativa discutem a importância da construção de um novo conjunto de literacias de mídia e informação no Ensino Superior. Carlos Alberto Prado da Silva Junior, Heliana Barbosa Fontenele e Antônio Nélson Rodrigues da Silva, por sua vez, apresentam os resultados da comparação entre duas formas de avaliação: uma tradicional, baseada em provas e testes, e outra que se vale de mapas conceituais. Os autores concluem que esta última pode auxiliar e aperfeiçoar a verificação da aprendizagem. 
Ainda entre os artigos, Grad+ abre generoso espaço para quatro trabalhos oriundos da área de Enfermagem. Nesse subconjunto, Isadora Cardoso Salles e Aurea Tamami Minagawa Toriyama avaliam se os graduandos compreendem e fazem uso adequado da Caderneta de Saúde da Criança, instrumento essencial de promoção da saúde infantil. Um grupo interdisciplinar de docentes descreve e analisa o processo de construção de um e-book sobre planejamento de ensino voltado à educação básica e profissional em Enfermagem. Alessandra Mazzo e um pool de pesquisadores compararam os resultados da aprendizagem de graduandos expostos a métodos de ensino/treino simulado de baixa e de alta fidelidade, num contexto de educação a distância mediante o uso de um AVA e da realização de videoconferências. Débora Rodrigues Vaz e outros cinco docentes avaliam o emprego de um heurístico (no caso em questão, um questionário aprofundado) com vistas a estimular a reflexão sobre o clima emocional, as relações interpessoais e as estratégias de comunicação de alunos em estágio curricular supervisionado no curso de licenciatura em Enfermagem da Escola de Enfermagem da Universidade de São Paulo.

Entre os relatos, avulta, a princípio, o texto de Suzana Ursi, Alessandra Fernandez Bizerra e Maria Aparecida Visconti, professoras do Instituto de Biociências da USP. Nessa colaboração, as autoras destacam a experiência docente em torno de uma disciplina voltada ao desenvolvimento, à introdução e à avaliação de estratégias didáticas para o magistério de Ciências e Biologia. Além de fomentar a autonomia dos estudantes, a iniciativa se vale de parcerias com instituições de ensino, formais e não formais, em que as propostas dos alunos podem ser efetivamente aplicadas. Nesse sentido, o trabalho por elas realizado prima por englobar os três pilares fundamentais da universidade: ensino, extensão e pesquisa.

Da Escola Politécnica, chama também a atenção a experiência de um grupo de docentes que reformulou as disciplinas de Comunicação Gráfica para Engenharia a partir do conceito de Project-based Learning (PBL). Mediante tal procedimento os estudantes são expostos a problemas cuja solução implica a execução de todas as etapas de um projeto, desde a concepção das linhas gerais até a fabricação de um determinado objeto. Em perspectiva correlata, Cristiane Aun Bertoldi, da FAU-USP, discorre sobre o uso da cerâmica como elemento facilitador da aprendizagem no que diz respeito à elaboração de modelos físicos e como ferramenta de projeto de um determinado produto. Além do caráter acessível e da possibilidade de manuseio sem grandes obstáculos, os materiais cerâmicos aproximariam o trabalho de obtenção de protótipos da realidade encontrada na produção fabril.

Os demais relatos que compõem esta edição confirmam o caráter prismático que define a amplitude do trabalho editorial realizado pela Grad+. Em meio ao caleidoscópio formado pelas demais colaborações, há o enfoque de diferentes práticas e estratégias de ensino, entre as quais se podem destacar: a produção de verbetes da Wikipédia e o uso da simulação como recursos pedagógicos; a importância da promoção de viagens didáticas; a proposta da FE-USP de criação de um Manual do Estagiário e de uma Portaria de Estágio no âmbito do programa de formação de professores da unidade; o emprego de metodologias ativas na educação odontológica, no curso de Nutrição da USP e em disciplina da EACH-USP centrada na problematização da realidade social; a utilização de filmes para a abordagem e fixação de conteúdos de fisiologia endócrina e, de modo correlato, a aplicação das Tecnologias da Informação e Comunicação (TICs) como ferramentas educacionais em um curso de licenciatura em Química do Instituto Federal Goiano; a criação de um clube de ciências digital interativo enquanto ponte para aproximar os alunos do Ensino Médio da universidade; o tratamento de temas e conceitos relacionados à eficiência energética em iniciativa de professores da USP de Pirassununga; a implementação de uma clínica ampliada de saúde bucal voltada à atenção básica; a articulação entre teoria e prática em trabalho de campo da área de Obstetrícia e entre formação e mundo do trabalho em ação de docentes da Escola de Enfermagem da USP de Ribeirão Preto. 
Ao olharmos para o horizonte e recobrarmos o fôlego, depois de traçado o percurso da edição de Grad+ que aqui apresentamos aos leitores, tudo leva a crer, oxalá, que nosso trabalho não se encerrará por aqui. A acolhida francamente favorável obtida pela revista e a crescente participação de professores, pós-doutorandos e pós-graduandos de diversas IES de todo o Brasil nas edições do Congresso de Graduação da USP sinalizam que ainda há muito o que percorrer, outros marcos a alcançar e novos aniversários a celebrar.

Por ora, é bem verdade, chegamos apenas às nossas bodas de papel. Trata-se de um feito modesto, mas marcante, de uma revista on-line que, cada vez mais, procura firmar-se na comunidade acadêmica e, assim, desempenhar de modo efetivo sua missão de valorizar pesquisas, experiências e boas práticas voltadas ao ensino de graduação. 